\title{
Advanced Stirling Radioisotope Generator Thermal Power Model in Thermal Desktop SINDA/FLUINT Analyzer
}

\author{
Xiao-Yen J. Wang ${ }^{1}$ and William A. Fabanich ${ }^{2}$ \\ NASA Glenn Research Center, Cleveland, Ohio, 44135 \\ and \\ Paul C. Schmitz ${ }^{3}$ \\ Power Computing Solutions Inc \\ Cleveland, Ohio, 44135
}

\begin{abstract}
This paper presents a three-dimensional Advanced Stirling Radioisotope Generator (ASRG) thermal power model that was built using the Thermal Desktop SINDA/FLUINT thermal analyzer. The model was correlated with ASRG engineering unit (EU) test data and ASRG flight unit predictions from Lockheed Martin's Ideas TMG thermal model. ASRG performance under (1) ASC hot-end temperatures, (2) ambient temperatures, and (3) years of mission for the general purpose heat source fuel decay was predicted using this model for the flight unit. The results were compared with those reported by Lockheed Martin and showed good agreement. In addition, the model was used to study the performance of the ASRG flight unit for operations on the ground and on the surface of Titan, and the concept of using gold film to reduce thermal loss through insulation was investigated.
\end{abstract}

\section{Introduction}

$\mathrm{T}$

HE Advanced Stirling Radioisotope Generator (ASRG) in Ref. 1-2 is being developed for multimission applications to provide a high-efficiency power source alternative to Radioisotope Thermoelectric Generators (RTG). The higher ASRG efficiency would reduce the required amount of radioisotope by roughly a factor of 4 in comparison to an RTG. Thus, because of the limited supply of Pu238, utilization of the ASRG could extend the radioisotope power available for future space science missions, such as deep-space missions, large planetary surface rovers, and systems in support of human exploration activities.

Figure 1 shows an overview of the ASRG and its interface with spacecraft (S/C). It consists of two advanced Stirling convertors (ASCs) enclosed in a housing. Each ASC has a general purpose heat source (GPHS) attached at the hot end to provide heat and a gas management valve and pressure relief device (PRD) at the top of the housing. The housing and its attached fins radiate heat to the environment, and the gas management valve is used to maintain a near-atmospheric pressure of inert gas inside the housing during ground operations. This gas is permanently vented to vacuum by the PRD for nominal operation in space. The ASC controller unit (ACU) is remotely located from the ASRG housing via an interconnect cable. It converts the alternating-current (AC) output from both ASCs from 28 to 34 VDC for a typical spacecraft electrical bus. The controller is used to maintain synchronized displacer/piston movement of the two directionally-opposed Stirling convertors to minimize induced disturbance to the spacecraft and its precision instrumentation.

\footnotetext{
${ }^{1}$ Aerospace Engineer, Thermal Systems Branch, 21000 Brookpark Rd./MS 86-12, AIAA member.

${ }^{2}$ Aerospace Engineer, Thermal Systems Branch, 21000 Brookpark Rd./MS 86-12.

${ }^{3}$ Aerospace Engineer, Power Computing Solutions Inc, 21000 Brookpark Rd./MS 301-2.
} 
An ASC consists of a free-piston Stirling convertor and an integral linear alternator that converts the piston reciprocating motion to electrical power output. The Stirling engine is a heat engine that operates by cyclic compression and expansion of a working fluid at different temperature levels such that there is net conversion of heat energy to mechanical work. The GPHS provides the heat to the heater head of the ASC. Helium is used as the working fluid and is hermetically contained within the convertor pressure vessel and is used in the various working stages of the ASC. The displacer shuttles helium between the expansion space, where heat is received, and the compression space, where the heat is rejected at the cold-side adapter flange (CSAF) attached to the housing. The changes in the pressures and volumes of the convertor working spaces drive a power piston that reciprocates to produce AC electrical power via a permanent-magnet linear alternator.

The ASRG DC power output depends on the following:

1) GPHS fuel load at the year of mission (YOM)

2) Thermal loss through insulation from the GPHS to the environment

3) ASC efficiency (i.e., Stirling engine efficiency $\times$ alternator efficiency), (defined as the ratio of the $\mathrm{AC}$ power output to heat going into the engine)

4) Cable and connector power loss

5) ACU power loss

For the effort described in this paper, a three-dimensional steady-state thermal power model was built to predict the ASRG AC power output. The ASC was modeled using the SAGE performance map that provided the ASC efficiency. With a given GPHS fuel load and defined ambient conditions, the AC power output was computed using the model. If it is assumed that the cable and connector power loss is $0.8 \%$ of the AC power and that the ACU efficiency is $87 \%$, the ASRG direct-current (DC) power can be computed as presented in this paper.

The initial purpose of building this model was to perform independent verification and validation on ASRG performance, including the current best estimate (CBE) ASRG DC power output (140 We) reported by Lockheed Martin (LM) and the ASRG minimum power output under the Department of Energy requirement of $130.5 \mathrm{We}$ DC for deep space (sink temperature $=4 \mathrm{~K}$ ). It was also intended to investigate the uncertainty of the ASRG power prediction for the flight unit, including factors such as the thermal loss through insulation and the ASC efficiency, as well as to investigate ASRG power output under different scenarios, such as during operations on the ground and on Titan's surface.

In the following sections, an overview of the current NASA Glenn Research Center (GRC) thermal model is given, followed by model correlation and validation. The current model results are compared with those reported by LM. Results for operation on the ground and on the surface of Titan are also reported. Finally, the conclusions are given.

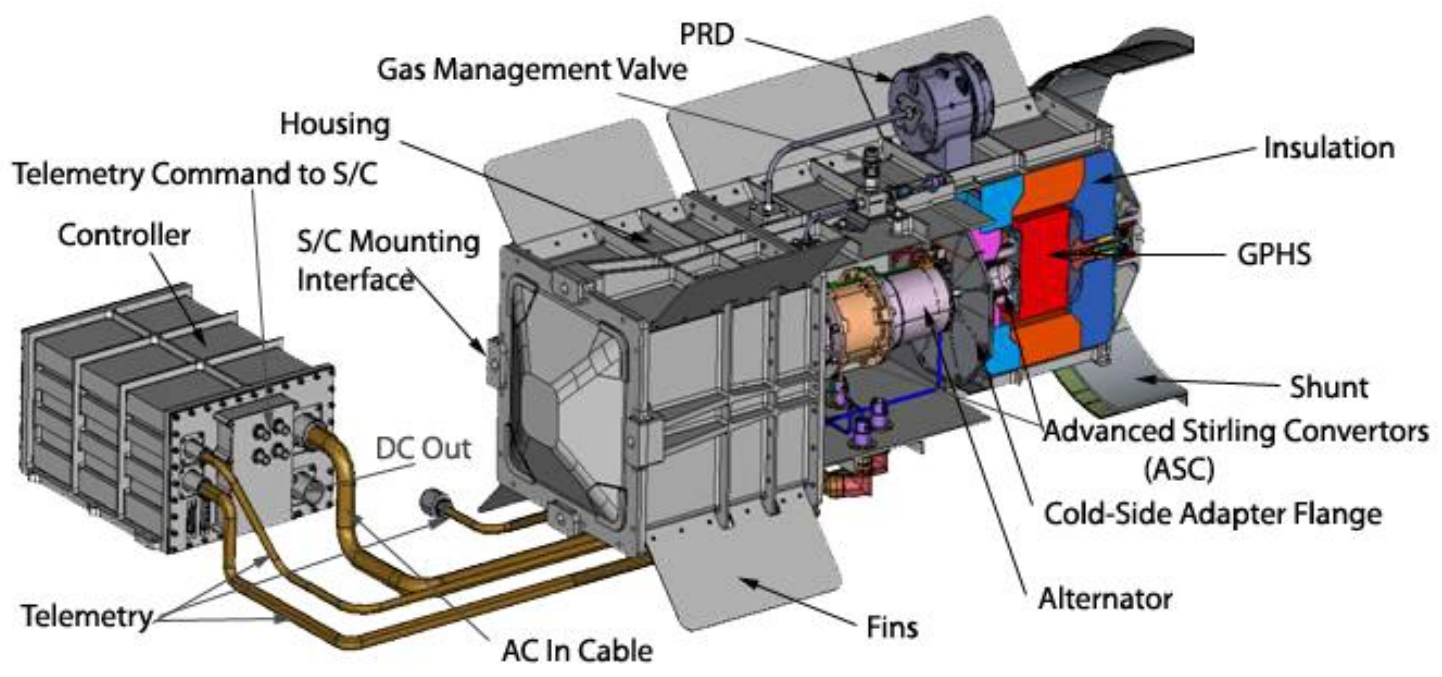

Figure 1. Overview of the ASRG components. 


\section{Overview of the ASRG thermal power model in Thermal Desktop}

The model was built using Thermal Desktop ${ }^{\circledR}$ (TD) and SINDA/FLUINT (C\&R Technologies) - a finite-difference and finite-element thermal analyzer. The TD is the front-end of SINDA/FLUINT. It provides a graphical user interface, builds the geometry, generates the mesh (finite difference and finite element), and defines the boundary conditions. It was coupled with the RadCAD® expansion pack (a thermal radiation analyzer also by $\mathrm{C} \& \mathrm{R}$ Technologies) that provides the ability to model radiation and orbit heating in various terrestrial and space environments (e.g., on planetary surfaces, on orbit, and along interplanetary trajectories.) MATLAB ${ }^{\circledR}$ (MathWorks) was used to interface with SINDA/FLUINT to perform the iterative run of SINDA/FLUINT with the ASC performance map to get a converged solution. The model has approximately 6,552 nodes and runs a few minutes for one case.

The geometry was based on LM's Pro-Engineer ${ }^{\circledR}$ ASRG-EU (engineering unit) Model. Modifications are made for the flight unit, including end domes, fin length (2.6 to 5 in.), and an ACU that is deattached from the housing. Figure 2 shows the housing for the ASRG EU and the flight unit. The internal components for the EU and flight unit are almost identical geometrically, with only minor differences that are not discussed here but are included in the model.

The ASC was modeled using a SAGE-generated performance map and was coupled into the thermal model. The ASC performance map shows the ASC net heat input $Q_{\text {in }}$, heat rejection $Q_{\text {rej, }}$, pressure vessel power output, alternator power output changes with hot-end temperature $T_{h}$, cold-end temperature $T_{c}$, and piston amplitude $A_{p}$. The map for the flight unit covers $T_{h}=680,760,800$, and $840{ }^{\circ} \mathrm{C} ; T_{c}=30,70$, and $110^{\circ} \mathrm{C}$; and three $A_{p}$ data points that are not given. In the thermal model, the ASC hot end is modeled as a thermal resistor, and ASC heat rejection $Q_{\text {rej }}$ is imposed as a boundary condition on the ASC cold end. The thermal resistance at the hot end $R_{6, \text { hot }}$ and $Q_{\text {rej }}$ are functions of $T_{h}, T_{c}$, and $A_{p}$. Logic was programmed into the model to allow the iteration of hot- and cold-end temperatures from the ASC performance curves. The output included alternator power output (looked up from the performance map). The iterative procedure used in the model is described in Fig. 3. The model can be run with two different ASC control algorithms: that is, with $A_{p}$ fixed or $T_{h}$ fixed. The three major steps in the iterative procedure follow: (1) give initial values of $R_{6, \text { hot }}$ and $Q_{\text {rej; }}$; (2) run the thermal model to compute temperatures and heat flows, such as $T_{h}, T_{c}$, and $Q_{\text {in }}$; and (3) use $T_{h}, T_{c}$, and $Q_{\text {in }}$ to update $R_{6, \text { hot }}$ and $Q_{\text {rej }}$ from the ASC performance map. The three steps are repeated until the differences of $R_{6, \text { hot }}$ and $Q_{\text {rej }}$ between two iterations are small enough $\left(<10^{-4}\right)$ to conclude that the solution has converged. Details on how $R_{6, \text { hot }}$ is defined and about the thermal circuit for ASRG are provided in Ref. 3.

The heat load on each GPHS was defined as $244 \mathrm{~W}$. Radiation emissivity between the GPHS and the insulation blocks was defined as 0.74 for the GPHS and 0.6 for the Microtherm® HT (Microtherm nv). The ambient sink temperature was $4 \mathrm{~K}$ in vacuum for the flight unit and $300 \mathrm{~K}$ for the engineering unit in air. The definitions of the conductance coefficients between each component were based on the interface configuration. The emissivity of the housing was 0.9 at the beginning of mission (BOM). The material properties of the CSAF and the Microtherm ${ }^{\circledR}$ HT were provided by Lockheed Martin; the other properties were obtained from an engineering database.

\section{Model correlation and validation}

\section{A. Correlation with EU testing data}

The three-dimensional thermal model described in Section II was correlated with the ASC-E2 test data. The ASC E2 SAGE map provided by Sunpower on May 13, 2009 was used in the model. Case 1 described in Table I, was used to correlate the model. With a given electric heat source power at both B inboard and A outboard (see Fig. 2), the model was run by adjusting contact resistance between the GPHS and the heater head and between the GPHS and the stud to match the test data of $T_{h}, T_{c}$, and alternator power output. The contact resistance that converged for case 1 was used with the same model to compute cases 2 and 3. The model results for cases 2 and 3 agree very well with the testing data, as shown in Table I. The assumptions and approach used in the current model were validated for the ASRG EU operating in air.

\section{B. Correlation with flight unit model-predicted results}

Because the interface between the GPHS and the heater head and between the GPHS and the stud are different for the EU and the flight unit, the contact resistance obtained in case 1 for the EU could not be used for the flight unit. The ASRG baseline design, $T_{h}=760{ }^{\circ} \mathrm{C}$, was used to correlate the model for the 
flight unit. The same approach was used to adjust the contact resistance between the GPHS and the stud and between the GPHS and the heater head to match the results reported by Lockheed Martin. Then, the converged contact resistance for the baseline case was used to run the model at different $T_{h}$ conditions: 680, 800 , and $840{ }^{\circ} \mathrm{C}$. Table II compares the results. In Fig. 4, the ASC net heat input and ASRG DC power output are plotted and compared with Lockheed Martin data. The maximum discrepancy in the DC power output is $1.2 \%$. The temperature contour of the ASRG for $T_{h}=760{ }^{\circ} \mathrm{C}$ is plotted in Fig. 5. It can be observed that the housing has its maximum temperature, $290.7 \mathrm{~K}$, at the interface between the CSAF and the housing and its minimum temperature, $270.0 \mathrm{~K}$, at the fin tip. Within the cavity of the GPHS and the insulation block, the temperature reaches $1156 \mathrm{~K}$. For the alternator, the maximum temperature is $335.0 \mathrm{~K}$.
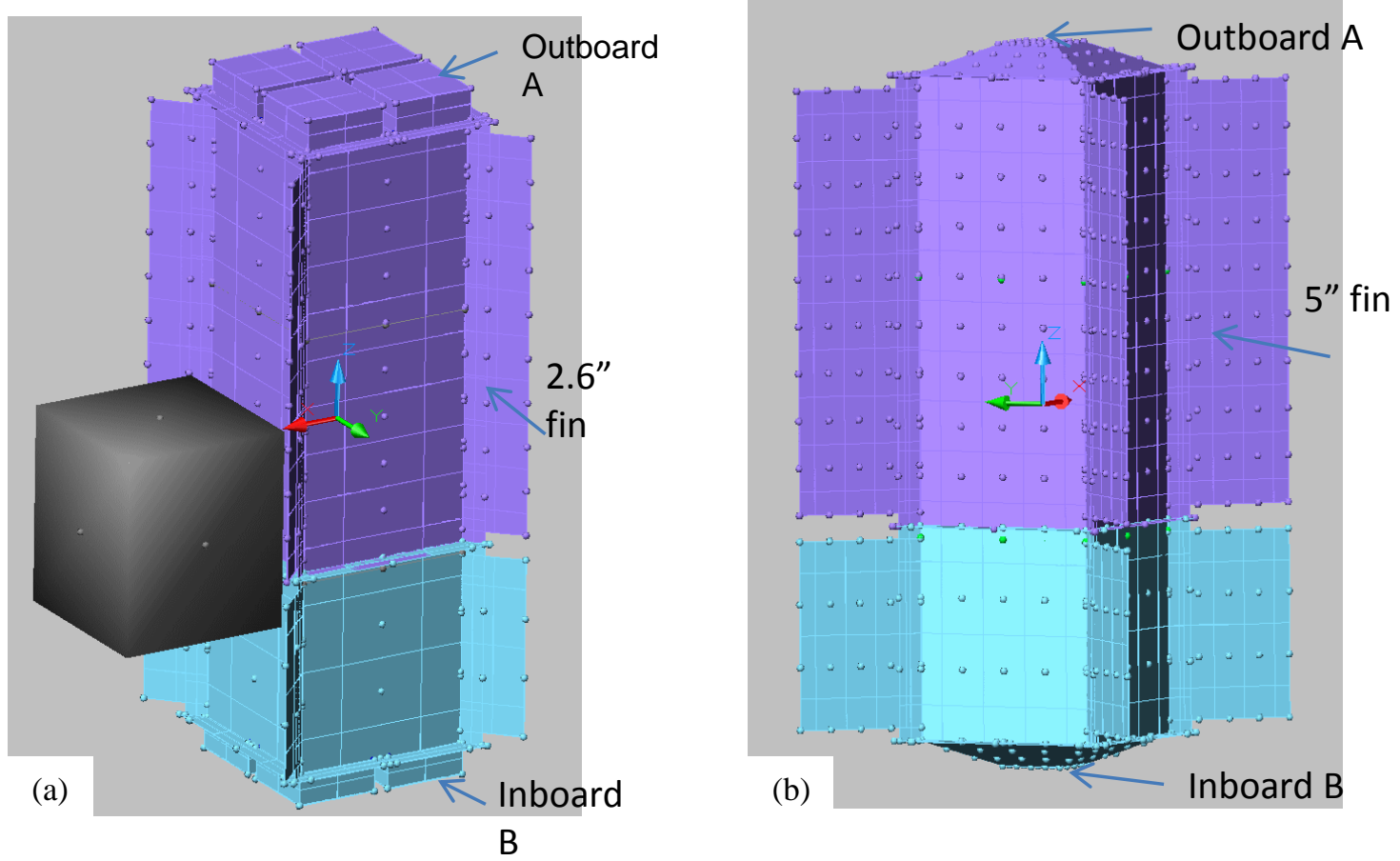

Figure 2. ASRG housing for (a) EU and (b) flight unit.

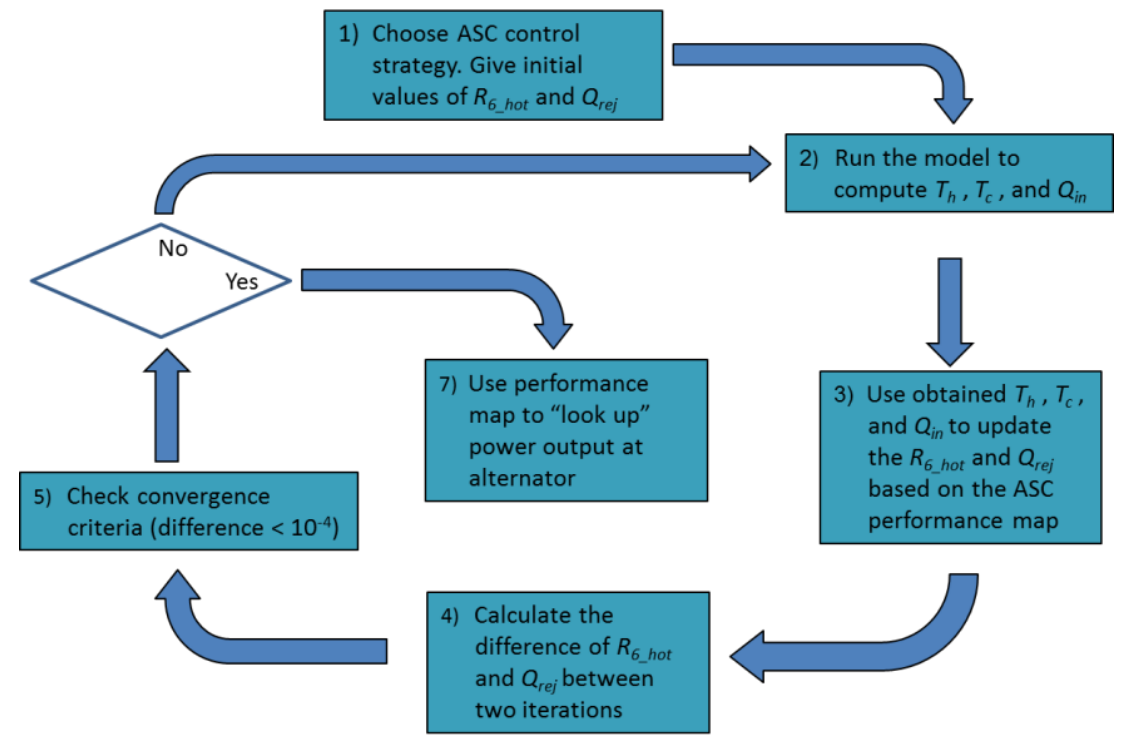

Figure 3. Iterative procedure to implement the logic in SINDA/FLUINT. 
Table I. Model results in comparison with test data for EU.

\begin{tabular}{|c|c|c|c|c|c|c|}
\hline & $\begin{array}{c}\text { Testing } \\
\text { data } \\
\text { Case } 1\end{array}$ & $\begin{array}{l}\text { Model } \\
\text { results } \\
\text { Case } 1\end{array}$ & $\begin{array}{c}\text { Testing } \\
\text { data } \\
\text { Case } 2\end{array}$ & $\begin{array}{l}\text { Model } \\
\text { results } \\
\text { Case } 2\end{array}$ & $\begin{array}{c}\text { Testing } \\
\text { data } \\
\text { Case } 3\end{array}$ & $\begin{array}{l}\text { Model } \\
\text { results } \\
\text { Case } 3\end{array}$ \\
\hline & A/B side & A/B side & A/B side & A/B side & A/B side & A/B side \\
\hline $\begin{array}{l}\text { Electric } \\
\text { heater } \\
\text { source } \\
\text { heat } \\
\text { input, Wt }\end{array}$ & $259 / 262$ & $259 / 262$ & $247 / 255$ & $247 / 255$ & $227 / 235$ & $227 / 235$ \\
\hline $\begin{array}{l}\text { ASC } \\
\text { piston } \\
\text { amp, mm }\end{array}$ & $4.22 / 4.22$ & $4.22 / 4.22$ & $4.26 / 4.27$ & $4.26 / 4.27$ & $4.01 / 4.00$ & $4.01 / 4.00$ \\
\hline $\begin{array}{l}\text { Thermal } \\
\text { loss, Wt }\end{array}$ & $N / A$ & $76.9 / 80.5$ & $\mathrm{~N} / \mathrm{A}$ & $70.9 / 76.5$ & $\mathrm{~N} / \mathrm{A}$ & $68.2 / 74$ \\
\hline $\begin{array}{l}\text { ASC net } \\
\text { heat } \\
\text { input, Wt }\end{array}$ & $N / A$ & 181.9/181.3 & $N / A$ & $175.9 / 178.5$ & $N / A$ & $158.7 / 161.4$ \\
\hline $\begin{array}{l}\text { ASC } \\
\text { alternator } \\
\text { output, } \\
\text { We }\end{array}$ & $65.0 / 64.0$ & $63.8 / 63.7$ & $61 / 62$ & $58.8 / 60.9$ & $52 / 54$ & $52.2 / 54.3$ \\
\hline$T_{h},{ }^{\circ} \mathrm{C}$ & $633 / 620$ & $634.5 / 632.3$ & $589 / 590$ & $583 / 600$ & $573 / 579$ & $571.4 / 590$ \\
\hline$T_{c},{ }^{\circ} \mathrm{C}$ & $60 / 58$ & $63 / 61.4$ & $60 / 58$ & $63 / 61$ & $55 / 54$ & $63 / 61$ \\
\hline
\end{tabular}


Table II. Model results for flight unit under different $T_{h}$ conditions.

\begin{tabular}{|c|c|c|c|c|c|c|c|c|}
\hline & \multicolumn{2}{|c|}{ Case 1} & \multicolumn{2}{|c|}{ Case 2} & \multicolumn{2}{|c|}{ Case 3} & \multicolumn{2}{|c|}{ Case 4} \\
\hline$T_{h}, \mathrm{C}$ & \multicolumn{2}{|c|}{680} & \multicolumn{2}{|c|}{760} & \multicolumn{2}{|c|}{800} & \multicolumn{2}{|c|}{840} \\
\hline \multirow{2}{*}{$\begin{array}{l}\text { GPHS fuel load, } \\
\text { Wt }\end{array}$} & \multicolumn{2}{|c|}{244} & \multicolumn{2}{|c|}{244} & \multicolumn{2}{|c|}{244} & \multicolumn{2}{|c|}{244} \\
\hline & LM & GRC & $L M$ & & LM & GRC & LM & GRC \\
\hline Thermal loss, Wt & 31.5 & 32.6 & 37.8 & 37.8 & 41.5 & 40.7 & 45.5 & 43.8 \\
\hline $\begin{array}{l}\text { ASC net heat } \\
\text { input, Wt }\end{array}$ & 212.5 & 211.4 & 206.2 & 206.2 & 202.5 & 203.3 & $\begin{array}{c}198 . \\
5\end{array}$ & 200.2 \\
\hline $\begin{array}{l}\text { ASC AC power, } \\
\text { We }\end{array}$ & N/A & 80.4 & 81.9 & 81.9 & $\mathrm{~N} / \mathrm{A}$ & 81.9 & N/A & 81.5 \\
\hline $\begin{array}{l}\text { ASRG DC power, } \\
\text { We }\end{array}$ & 138.5 & 137.2 & 140 & 139.8 & 138.5 & 139.8 & $\begin{array}{c}137 . \\
5\end{array}$ & 139.1 \\
\hline $\begin{array}{l}\text { Difference, } \\
\text { We (percent) }\end{array}$ & & $\begin{array}{c}-1.3 \\
(-0.94 \%)\end{array}$ & & $\begin{array}{c}-0.2 \\
(-0.14 \%)\end{array}$ & & $\begin{array}{c}1.3 \\
(0.94 \%)\end{array}$ & N/A & $\begin{array}{c}1.6 \\
(1.16 \%)\end{array}$ \\
\hline$T_{c},{ }^{\circ} \mathrm{C}$ & $\mathrm{N} / \mathrm{A}$ & 35.6 & 35.0 & 33.4 & N/A & 32.8 & N/A & 32.3 \\
\hline$T_{s},{ }^{\circ} \mathrm{C}$ & $\mathrm{N} / \mathrm{A}$ & 805.6 & 876.0 & 880.0 & $\mathrm{~N} / \mathrm{A}$ & 917.7 & N/A & 955.3 \\
\hline
\end{tabular}
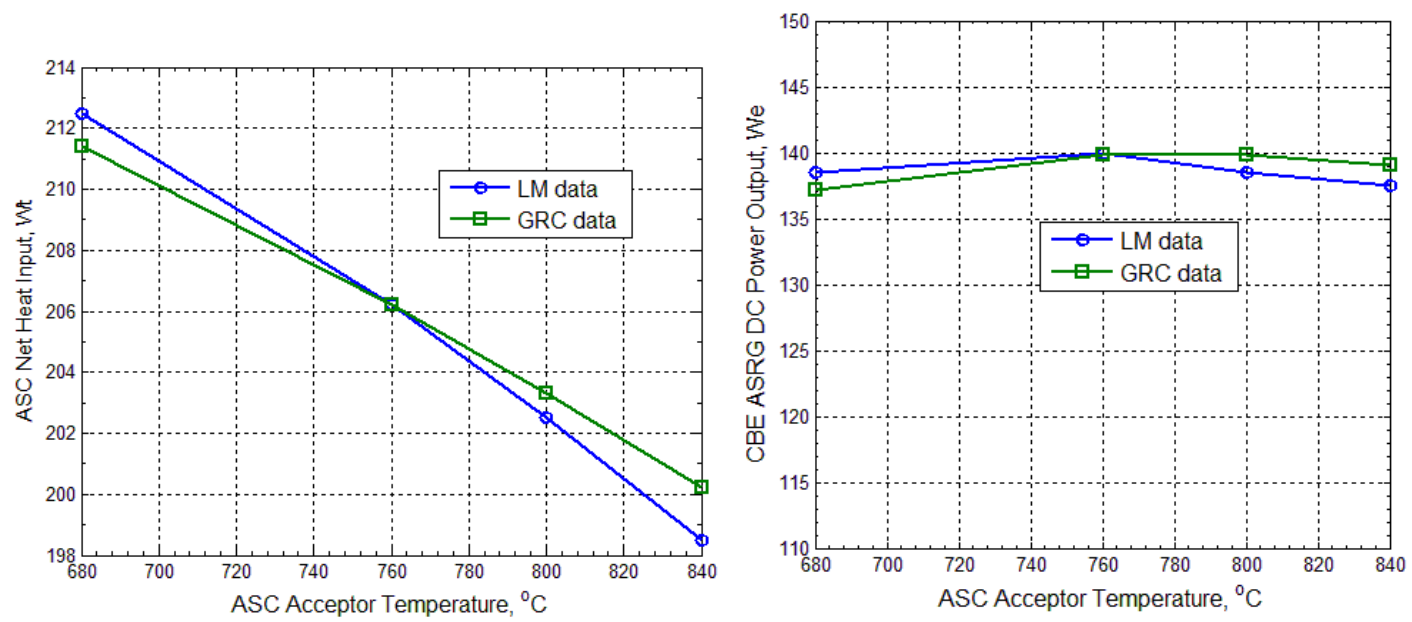

Figure 4. Comparison of LM results and current model results. 

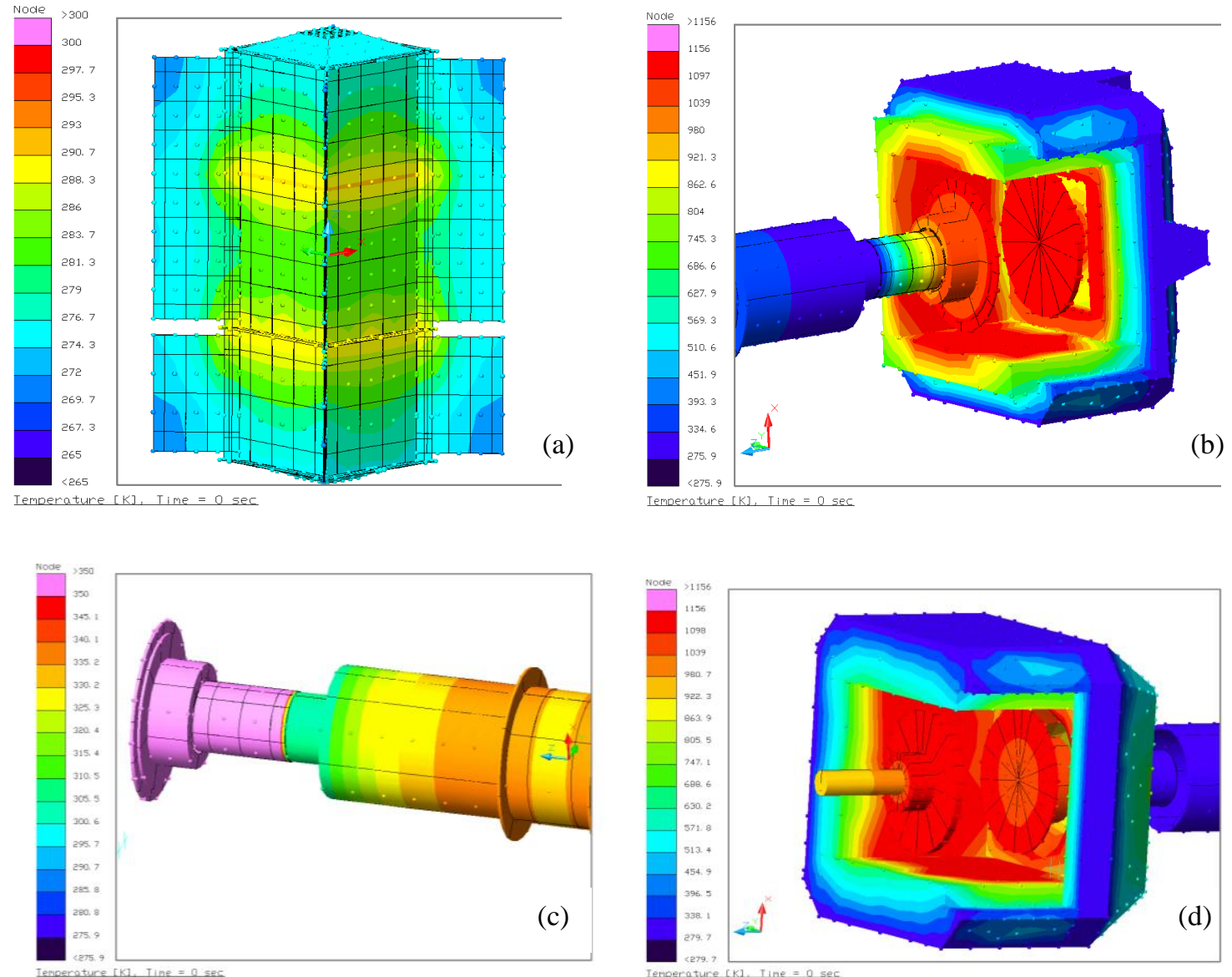

Figure 5. Temperature contour of the ASRG for $T_{h}=760^{\circ} \mathrm{C}$ for (a) ASRG housing, (b) ASC and insulation blocks (B inboard), (c) alternator, and (d) insulation block (A outboard).

\section{B.1 ASRG Performance Characteristics under Different Ambient Sink Temperatures}

For different missions, the environment could be very different. Variations in the ambient sink temperature $T_{a}$ from 4 to $300 \mathrm{~K}$, as shown in Ref. 4, were investigated. An equivalent sink temperature of $200 \mathrm{~K}$ was used for the environment on Mars. For a Venus flyby, a sink temperature of $300 \mathrm{~K}$ was used. The GPHS fuel load was assumed to be $244 \mathrm{~W}$ and $T_{h}=760^{\circ} \mathrm{C}$. Table III compares the LM results with the current model (GRC) results. Figure 6 compares the ASRG DC power output and shows that acceptable agreement was achieved.

Table III. ASRG DC power output under different sink temperatures.

\begin{tabular}{|c|c|c|c|c|c|c|c|c|}
\hline$T_{a}, \mathrm{~K}$ & \multicolumn{2}{|c|}{4} & \multicolumn{2}{|c|}{100} & \multicolumn{2}{|c|}{200} & \multicolumn{2}{|c|}{300} \\
\hline GPHS fuel load, Wt & \multicolumn{2}{|c|}{244} & \multicolumn{2}{|c|}{244} & \multicolumn{2}{|c|}{244} & \multicolumn{2}{|c|}{244} \\
\hline & LM & & LM & GRC & LM & GRC & LM & GRC \\
\hline ASRG DC power, We & 140 & 139.8 & 138.5 & 139.5 & 134.5 & 134.9 & 120.5 & 120.4 \\
\hline
\end{tabular}




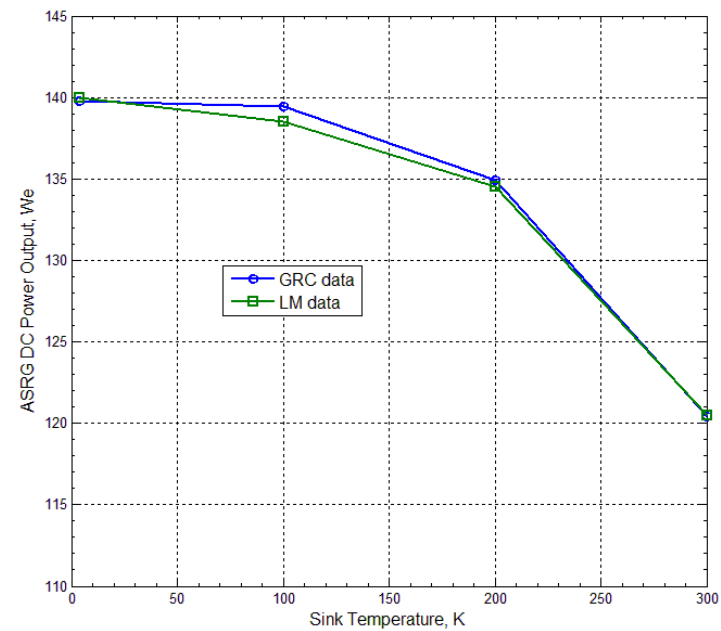

Figure 6. Comparison of ASRG DC power output versus sink temperatures.

\section{B.2 ASRG Performance Characteristics for YOM}

The ASRG power output was studied for the YOM since the GPHS fuel decays with time. A 17-year time frame was considered that would include up to three years of storage and 14 years on mission. The fuel decay rate was computed as

$$
\text { YOM GPHS fuel load }=\text { BOM fuel load } \times 0.5^{\text {YOM/7.74 }}
$$

A BOM fuel load of $244 \mathrm{~W}$ was used in the calculation. Table IV shows the results for YOM $=0,7$, and 14 years with $T_{h}=760{ }^{\circ} \mathrm{C}$ in comparison to data reported by LM for the deep space case, showing acceptable agreement.

Table IV. ASRG DC power output for YOM.

\begin{tabular}{|c|c|c|c|c|c|c|}
\hline YOM, years & \multicolumn{2}{|c|}{ вом } & \multicolumn{2}{|c|}{7} & \multicolumn{2}{|c|}{14} \\
\hline \multirow{2}{*}{ GPHS fuel load, Wt } & \multicolumn{2}{|c|}{244} & \multicolumn{2}{|c|}{230.9} & \multicolumn{2}{|c|}{218.5} \\
\hline & LM & & LM & GRC & LM & GRC \\
\hline ASRG DC power output, We & 140 & 139.8 & 131 & 130.8 & 121.5 & 122.0 \\
\hline
\end{tabular}

\section{Model Prediction for ASRG Power Output during Launch Integration at the NASA Kennedy Space Center}

Investigation of ASRG thermal conditions were assessed during the ground integration of the ASRG with a spacecraft both at the Payload Hazardous Servicing Facility (PHSF) and the Vertical Integration Facility described in Ref. 5. The ASRG could be exposed to following thermal environments:

1) Cloudy: ambient temperature, $28^{\circ} \mathrm{C}\left(81.8^{\circ} \mathrm{F}\right)$; sky temperature, $28^{\circ} \mathrm{C}\left(81.8^{\circ} \mathrm{F}\right)$

2) Sunny: ambient temperature, $35^{\circ} \mathrm{C}\left(94.4^{\circ} \mathrm{F}\right)$; sky temperature, $37^{\circ} \mathrm{C}\left(98.0^{\circ} \mathrm{F}\right)$

3) Natural Convection: heat transfer coefficient, $\mathrm{h}=5$ and $25 \mathrm{~W} / \mathrm{m}^{2}-\mathrm{K}$ for cases 1 and 2 , respectively.

The model was run with both radiation and convection boundary conditions for the housing. The results are listed in Table V. The worst case is case 1: sunny with $h=5 \mathrm{~W} / \mathrm{m}^{2}-\mathrm{K}$, showing that the temperature is under the limit $\left(120^{\circ} \mathrm{C}\right)$. 
Table V. Model results for operations on the ground.

\begin{tabular}{|l|c|c|c|c|}
\hline & $\begin{array}{c}\text { Sunny } \\
\text { Case 1 }\end{array}$ & $\begin{array}{l}\text { Sunny } \\
\text { Case 2 }\end{array}$ & $\begin{array}{c}\text { Cloudy } \\
\text { Case 1 }\end{array}$ & $\begin{array}{c}\text { Cloudy } \\
\text { Case2 }\end{array}$ \\
\hline GPHS fuel load, Wt & 244.0 & 244.0 & 244.0 & 244.0 \\
\hline ASC net heat input, Wt & 183.5 & 182.9 & 183.3 & 182.6 \\
\hline ASC alternator output, We & 64.0 & 66.8 & 64.9 & 67.9 \\
\hline ASRG DC power output, We & 108.8 & 113.6 & 110.5 & 115.6 \\
\hline$T_{h}{ }^{\circ} \mathrm{C}$ & 760 & 760 & 760 & 760 \\
\hline$T_{c,}{ }^{\circ} \mathrm{C}$ & $91\left(194^{\circ} \mathrm{F}\right)$ & $71\left(158^{\circ} \mathrm{F}\right)$ & $84\left(182^{\circ} \mathrm{F}\right)$ & $62\left(143^{\circ} \mathrm{F}\right)$ \\
\hline$h, \mathrm{~W} / \mathrm{m}^{2}-\mathrm{K}$ & 5 & 25 & 5 & 25 \\
\hline
\end{tabular}

\section{Model Prediction for ASRG Power Output on the Surface of Titan}

On Titan's surface, the ambient temperature is $90 \mathrm{~K}\left(-183^{\circ} \mathrm{C}\right)$ and the sky temperature is $94 \mathrm{~K}(-179$ ${ }^{\circ} \mathrm{C}$ ) in Ref. 6. The wind speed could be between 0 to $2 \mathrm{~m} / \mathrm{s}$. The convective heat transfer coefficients of $h=$ $0,6,12$, and $24 \mathrm{~W} / \mathrm{m}^{2}-\mathrm{K}$ were used in this study. The results are listed in Table VI, showing that the ASRG could get very cold $\left(-148{ }^{\circ} \mathrm{C}\right.$ for the worst case). Results indicate that the ASRG lower temperature design limit would be exceeded if it were exposed on Titan's surface without shielding.

Table VI. Model results for operation on Titan's surface.

\begin{tabular}{|l|c|c|c|c|}
\hline & Case 1 & Case 2 & Case 3 & Case 4 \\
\hline GPHS fuel load, Wt & 244.0 & 244.0 & 244.0 & 244.0 \\
\hline ASC net heat input, Wt & 185.5 & 180.1 & 179 & 178.4 \\
\hline ASC alternator output, We & 73.1 & 71.1 & 70.6 & 70.3 \\
\hline ASRG DC power output, We & 124.6 & 121.2 & 120.2 & 119.7 \\
\hline$T_{h}{ }^{\circ} \mathrm{C}$ & 760 & 760 & 760 & 760 \\
\hline$T_{c}{ }^{\circ} \mathrm{C}$ & 34 & -101 & -131 & -148 \\
\hline$h, \mathrm{~W} / \mathrm{m}^{2}-\mathrm{K}$ & 0 & 6 & 12 & 24 \\
\hline
\end{tabular}




\section{Model Prediction for ASRG Power Output with/without Gold Film}

One concept for reducing the thermal loss through insulation is to install gold-film multilayer insulation (MLI) between the existing insulation and the GPHS. The gold film has very low emissivity (0.02). Results listed in Table VII show significant ASRG power gain when the gold film concept is used in different environments.

Table VII. Comparison of results with and without gold film MLI.

\begin{tabular}{|c|c|c|c|c|c|c|}
\hline Environment & \multicolumn{2}{|c|}{ Vacuum } & \multicolumn{2}{|c|}{$\begin{array}{l}\text { On the ground } \\
\text { (1 atm Ar) }\end{array}$} & \multicolumn{2}{|c|}{$\begin{array}{l}\text { On Titan's surface } \\
\left(1.5 \mathrm{~atm} \mathrm{~N}_{2}\right)\end{array}$} \\
\hline GPHS fuel load, Wt & \multicolumn{2}{|c|}{244} & \multicolumn{2}{|c|}{244} & \multicolumn{2}{|c|}{244} \\
\hline Gold film & No & Yes & No & Yes & No & Yes \\
\hline Thermal loss, Wt & 37.8 & 31.6 & 62.3 & 46.8 & 58.6 & 45.1 \\
\hline ASC net heat input, Wt & 206.2 & 212.4 & 181.7 & 197.2 & 185.4 & 198.9 \\
\hline ASC AC power output, We & 81.9 & 84.8 & 71.3 & 78.3 & 73.2 & 78.7 \\
\hline $\begin{array}{l}\text { ASRG DC power output, } \\
\text { We }\end{array}$ & 139.8 & 144.7 & 121.5 & 133.6 & 124.6 & 134.3 \\
\hline$h, \mathrm{~W} / \mathrm{m}^{2}-\mathrm{K}$ & 0 & 0 & 25 & 25 & 0 & 0 \\
\hline
\end{tabular}

\section{Conclusions}

A three-dimensional steady-state thermal power model of the ASRG was presented. The model was correlated with Lockheed Martin's predicted results for the ASRG flight unit and test data for the ASRG EU. ASRG power versus the year of mission and ambient sink temperature, $T_{a}$, are compared with Lockheed Martin's data. Reasonable agreement was achieved for all cases. The model was used to run the following cases: (1) ASRG operations on the ground - Results showed that the ASRG temperature was within the limit; (2) ASRG operations on Titan's surface - Because of convection, results indicate it would be too cold for the ASRG if it were exposed on Titan's surface; and (3) use of the gold-film multilayer insulation concept - The gold film could potentially save a significant amount of thermal loss through insulation, especially when the ASRG is not in a vacuum environment.

\section{Acknowledgments}

The first author thanks Edward Lewandowski and Robert Cataldo of NASA GRC for providing critical data and technical discussions for this modeling effort and reviewing this paper; and Jim Withrow and Christopher Steffen of GRC for supporting this effort under the Radioisotope Power System Program.

\section{References}

1. Chan, J., Wood, J. G., and Schreiber, J. G., "Development of Advanced Stirling Radioisotope Generator for Space Exploration," Space Technology and Applications International Forum (STAIF), Feb. 11-15, 2007.

2. Lewandowski, E. J., and Schreiber, J. G., "Testing to Characterize the Advanced Stirling Radioisotope Generator Engineering Unit," 8th International Energy Conversion Engineering Conference (IECEC), Nashville, TN July 25-28, 2010.

3. Wang, X.Y., "Advanced Stirling Radioisotope Generator (ASRG) Thermal Power Model in MATLAB ${ }^{\circledR}, " 9 t h$ International Energy Conversion Engineering Conference (IECEC), San Diego, CA, 2011. 
4. ASRG User ICD, 912IC002085, Lockheed Martin, May 2010.

5. Cataldo, R.L. et al., "Concept of Operation for the Advanced Stirling Radioisotope Generator", presented at NETS conference, March, 2012.

6. Lorenz, R.D., "A simple model for radioisotope power system performance in the Titan Environment", JBIS, 63, $9-14$. 